\title{
Steroids and/or cytotoxic agents should be used early in the management of patients with IPF - The con argument
}

\author{
Stephen K Field MD CM
}

$\mathrm{T}_{\mathrm{R}}^{\mathrm{h}}$ he recently published American Thoracic Society/European Respiratory Society statement distinguishes idiopathic pulmonary fibrosis (IPF), also known as usual interstitial pneumonia (UIP), from the other idiopathic interstitial pneumonias (IIPs) (1). Although the current classification of IIPs is different from the one developed by Liebow and Carrington (2) in the 1960s, the description of UIP has not changed, and it is still recognized as having distinctive clinical and pathological features that distinguish it from the other IIPs. IPF responds differently to systemic corticosteroid (steroid) therapy and has a different prognosis than the other IIPs, such as nonspecific interstitial pneumonitis, which previously were felt to be variants of the same condition $(1,3,4)$. Despite therapy, most patients with IPF experience a progressive decline in pulmonary function, leading to respiratory failure and death, unless they undergo lung transplantation.

IPF must be distinguished from the other IIPs so that it can be managed appropriately (1). The diagnosis of IPF or UIP should be confirmed by surgical biopsy or by the presence of typical high resolution computed tomography findings in patients who meet the American Thoracic Society/European Respiratory Society criteria for the diagnosis of IPF $(1,3)$. It must be emphasized that IPF, not one of the other IIPs, is the subject of this debate (1).

The attraction to intervene and treat, rather than observe, a patient with a progressive and life-threatening disease is obvious. Before the recent recognition that IPF was a fibrotic condition rather than an inflammatory condition, it was regularly treated with steroids and other immunosuppressive medications, unlike the other IIPs that it had previously been confused with (5-7). The results of steroid treatment in patients with IPF have been reported since the 1950s (8). Unfortunately, none of these were prospective, randomized, controlled trials, and most of the studies did not distinguish IPF from the other IIPs (7). Approximately 25\% of the patients in these trials responded to steroid treatment (7). Some of this apparent improvement with steroid therapy was due to misdiagnosis of patients with steroid responsive IIPs and their inclusion in these studies. In controlled trials, the addition of cytotoxics, either azathioprine or cyclophosphamide, to steroids did not improve the outcome in IPF patients (7).

Several recent studies indicate that the prognosis of patients with IPF is related to the rate of pulmonary function decline and pathological features of fibrosis, such as fibrogenic foci, rather than to therapy $(5,9-13)$. Dismal results were reported in the studies of steroid therapy that were limited to patients with IPF and excluded patients with steroid-responsive IIPs (7). Less than $10 \%$ of the patients with IPF responded to therapy with steroids (7). These results are discouraging compared with a longitudinal study that demonstrated that $15 \%$ of patients with IPF were stable after two years without any therapy (14). Because none of the treatment trials were placebo controlled, it is likely that the apparent improvement with treatment was due to the variability in the rate of functional decline known to occur in these patients $(7,8)$. Patients are more likely to be started on treatment during a period of more rapid functional decline. The subsequent period of relative stability and even slight improvement due to the natural course of the illness may be attributed to therapy. This effect has been casually referred to as 'regression to the mean' (15). This suggests that treatment with steroids, with or without cytotoxic therapy, is no better than supportive therapy. A review of nearly 500 patients with IPF seen at the Mayo Clinic found that survival was no better in patients treated with prednisone than in those receiving best supportive care (16). Early treatment of IPF with steroids and cytotoxic medications exposes patients to the serious side effects of these medications without any therapeutic benefits at a time when they would otherwise still have a reasonable quality of life.

Virtually all patients treated chronically with high dose steroids experience important side effects (17). Some of these cause significant morbidity, such as glucose intolerance, hypertension, avascular necrosis, impaired wound healing, myopathy, osteoporosis, cataracts, glaucoma, mood changes and psychosis, and require additional therapy. Some, such as adrenal suppression, gastrointestinal bleeding, and immunosuppression and opportunistic infections, may be life threatening. Cytotoxic medications also cause potentially fatal adverse effects, including bone marrow suppression, immunosuppression and opportunistic infections, and renal and liver toxicity; they also increase the risk of a variety of malignancies, including lymphoma and bladder cancer. Moreover, patients on steroids and/or cytotoxic medications require other medications to treat their potential adverse effects and they, in turn, also cause adverse effects. Cotrimoxasole, given to prevent Pneumocystis pneumonii pneumonia, may cause skin rashes and bone marrow suppression; antituberculous medications may cause liver toxicity; rifampin interferes with the metabolism of many other medications, including steroids; and biphosphonates, given to prevent steroid induced osteoporosis, may cause dyspepsia and gastroesophageal reflux.

Division of Respirology, University of Calgary, Health Science Centre, Calgary, Alberta

Correspondence: Dr Stephen Field, Division of Respirology, University of Calgary, Health Science Centre, 3330 Hospital Drive Northwest,

Calgary, Alberta T2N 4N1. Telephone 403-220-8722, fax 403-283-6151, e-mail sfield@ucalgary.ca 
The only proven successful treatment for IPF is lung transplantation, and the adverse effects of chronic steroid and cytotoxic therapy, including weight gain, impaired wound healing and osteoporosis, may preclude successful transplantation (18-20).

Some have argued that IPF should be treated early, before extensive fibrosis develops. There are no data to support this recommendation, and there is no evidence that early treatment prolongs life. This unproven approach would subject patients to the various morbidities associated with steroid and cytotoxic therapy, would disrupt their lives and would impair their quality of life before their lives were disrupted by the illness itself. Moreover, adverse effects from early treatment, such as opportunistic infection, would kill some patients before they experienced significant impairment from IPF.

The leading international IPF investigators have moved beyond recommending steroids and cytotoxic therapy for the treatment of their patients (21-23): "The committee concludes that no data exist that adequately document any of the current treatment approaches improve survival or quality of life for patients with IPF" (1). A number of editorials in the leading peer reviewed journals have acknowledged that steroid and cytotoxic therapy is ineffective, and that new therapies are necessary $(24,25)$. They emphasized that IPF is a fibrotic rather than an inflammatory disease, and that antifibrotic therapy is necessary to treat this condition. Recently, there have been

\section{REFERENCES}

1. American Thoracic Society; European Respiratory Society. American Thoracic Society/European Respiratory Society International Multidisciplinary Consensus Classification of the Idiopathic Interstitial Pneumonias. Am J Respir Crit Care Med 2002;165:277-304.

2. Liebow AA, Carrington CB. The interstitial pneumonias. In: Simon M, Potchen EJ, LeMay M eds. Frontiers of Pulmonary Radiology. New York: Grune and Stratton Inc, 1969:102-41.

3. American Thoracic Society. Idiopathic pulmonary fibrosis: Diagnosis and treatment. International consensus statement. American Thoracic Society (ATS) and the European Respiratory Society (ERS). Am J Respir Crit Care Med 2000;162:646-64.

4. Kamp DW. Idiopathic pulmonary fibrosis. The inflammation hypothesis revisited. Chest 2003;124:1187-90.

5. Selman M, King TE, Pardo A. Idiopathic pulmonary fibrosis: Prevailing and evolving hypotheses about its pathogenesis and implications for therapy. Ann Intern Med 2001;134:136-51.

6. Lynch JP III, White E, Flaherty K. Corticosteroids in idiopathic pulmonary fibrosis. Curr Opin Pulm Med 2001;7:298-308.

7. Collard HR, King TE Jr. Demystifying idiopathic interstitial pneumonia. Arch Intern Med 2003;163:17-29.

8. Mapel DW, Samet JM, Coultas DB. Corticosteroids and the treatment of idiopathic pulmonary fibrosis. Past, present, and future. Chest 1996;110:1058-67.

9. Nicholson AG, Fulford LG, Colby TV, du Bois RM, Hansell DM, Wells AU. The relationship between individual histologic features and disease progression in idiopathic pulmonary fibrosis. Am J Respir Crit Care Med 2002;166:173-7.

10. Latsi PI, du Bois RM, Nicholson AG, et al. Fibrotic idiopathic interstitial pneumonia: The prognostic value of longitudinal functional trends. Am J Respir Crit Care Med 2003;168:531-7.

11. Collard HR, King TE Jr, Bartelson BB, Vourlekis JS, Schwarz MI, Brown KK. Changes in clinical and physiologic variables predict survival in idiopathic pulmonary fibrosis. Am J Respir Crit Care Med 2003; 168:538-42.

12. Hanson D, Winterbauer RH, Kirtland SH, Wu R. Changes in pulmonary function test results after 1 year of therapy as predictors of survival in patients with idiopathic pulmonary fibrosis. Chest 1995;108:305-10.

13. Flaherty KR, Mumford JA, Murray S, et al. Prognostic implications of physiologic and radiographic changes in idiopathic interstitial pneumonia. Am J Respir Crit Care Med 2003;168:543-8. reports from preliminary trials of a variety of antifibrotic medications for the treatment of IPF, including colchicine, pirfenidone and interferon-gamma (20-22).

A recent editorial stated that it is necessary to acknowledge that current therapy is ineffective to encourage the search for new therapies (25). It goes on to suggest that growth factors, regulators of apoptosis, chemokines and cytokines have been implicated in the progression of IPF and may need to be targeted in its therapy. The imbalance between the mediators of extracellular matrix deposition, such as transforming growth factor-beta- 1 , and mediators of extracellular matrix proteolysis, including the matrix metalloproteinases, may play a role in the pathogenesis of pulmonary fibrosis and may need to be targeted to successfully treat IPF (25).

In conclusion, corticosteroids and cytotoxic medications are toxic drugs that cause serious, sometimes life-threatening adverse effects, and are not effective in the treatment of IPF. Patients taking these medications require extra monitoring and testing for adverse effects. There is no evidence that they improve survival or quality of life. If patients begin taking these medications early in the course of their disease, their lives may be disrupted while they are relatively well and they may experience manifold, important adverse effects earlier in the course of their illness. Moreover, early and longer use of these medications reduces the likelihood that patients will experience a good quality of life after lung transplantation. They should not be used in the management of patients with IPF early or at any time.

14. Xaubet A, Agusti C, Luburich P, et al. Is it necessary to treat all patients with idiopathic pulmonary fibrosis? Sarcoidosis Vasc Diffuse Lung Dis 2001;18:289-95.

15. Kienle GS, Kiene H. Placebo effect and placebo concept: A critical methodological and conceptual analysis of reports on the magnitude of the placebo effect. Altern Ther Health Med 1996;2:39-54.

16. Douglas WW, Ryu JH, Schroeder DR. Idiopathic pulmonary fibrosis. Impact of oxygen and colchicine, prednisone, or no therapy on survival. Am J Respir Crit Care Med 2000;161:1172-8.

17. Flaherty KR, Toews GB, Lynch JP 3rd, et al. Steroids in idiopathic pulmonary fibrosis: A prospective assessment of adverse reactions, response to therapy, and survival. Am J Med 2001;110:278-82.

18. Sulica R, Teirstein A, Padilla ML. Lung transplantation in interstitial lung disease. Curr Opin Pulm Med 2001;7:314-22.

19. Charman SC, Sharples LD, McNeil KD, Wallwork J. Assessment of survival benefit after lung transplantation by patient diagnosis. J Heart Lung Transplant 2002;21:226-32.

20. Thabut G, Mal H, Castier Y, et al. Survival benefit of lung transplantation for patients with idiopathic pulmonary fibrosis. J Thorac Cardiovasc Surg 2003;126:469-75.

21. Douglas WW, Ryu JH, Swensen SJ, et al. Colchicine versus prednisone in the treatment of idiopathic pulmonary fibrosis. A randomized prospective study. Members of the Lung Study Group. Am J Respir Crit Care Med 1998;158:220-5.

22. Raghu G, Johnson WG, Lockhart D, Mageto Y. Treatment of idiopathic pulmonary fibrosis with a new antifibrotic agent, pirfenidone: Results of a prospective, open-label phase II study. Am J Respir Crit Care Med 1999;159:1061-9.

23. Ziesche R, Hofbauer E, Wittmann K, Petkov V, Block LH. A preliminary study of long-term treatment with interferon gamma-1b and low-dose prednisolone in patients with idiopathic pulmonary fibrosis. New Engl J Med 1999;341:1264-9.

24. Selman M. From anti-inflammatory drugs through antifibrotic agents to lung transplantation. A long road of research, clinical attempts, and failures in the treatment of idiopathic pulmonary fibrosis. Chest 2002;122:759-61.

25. Cook DN, Brass DM, Schwartz DA. A matrix for new ideas in pulmonary fibrosis. Am J Respir Cell Mol Biol 2002;27:122-4. 


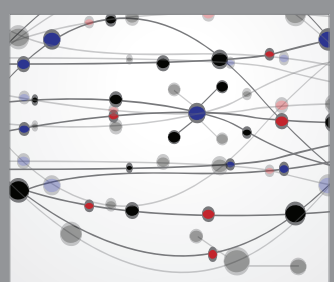

The Scientific World Journal
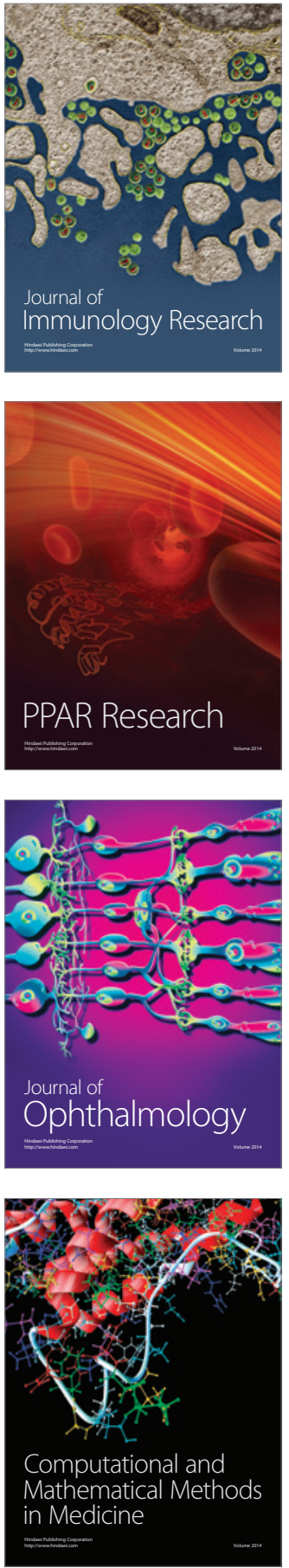

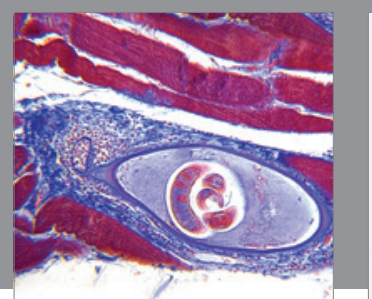

Gastroenterology Research and Practice

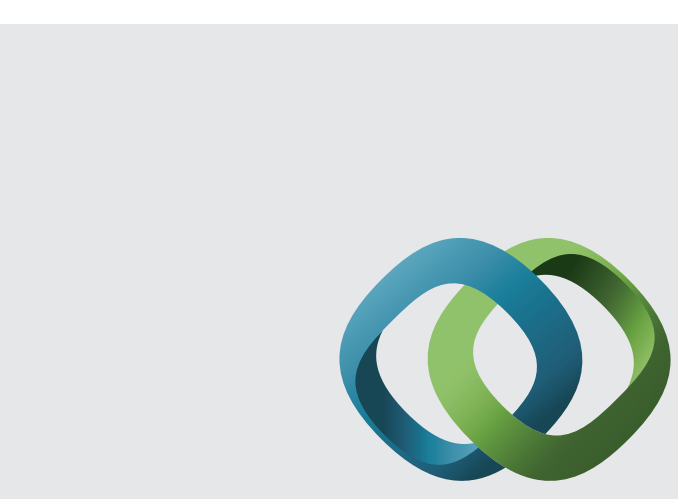

\section{Hindawi}

Submit your manuscripts at

http://www.hindawi.com
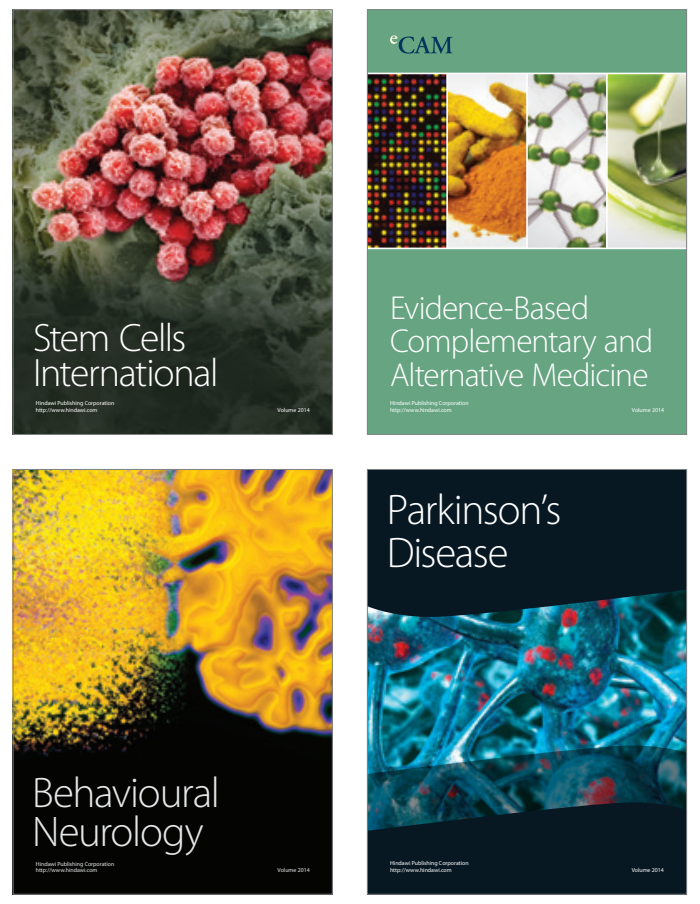
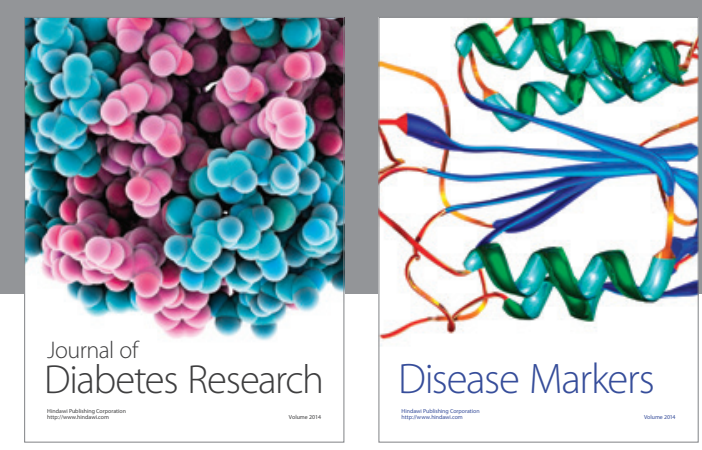

Disease Markers
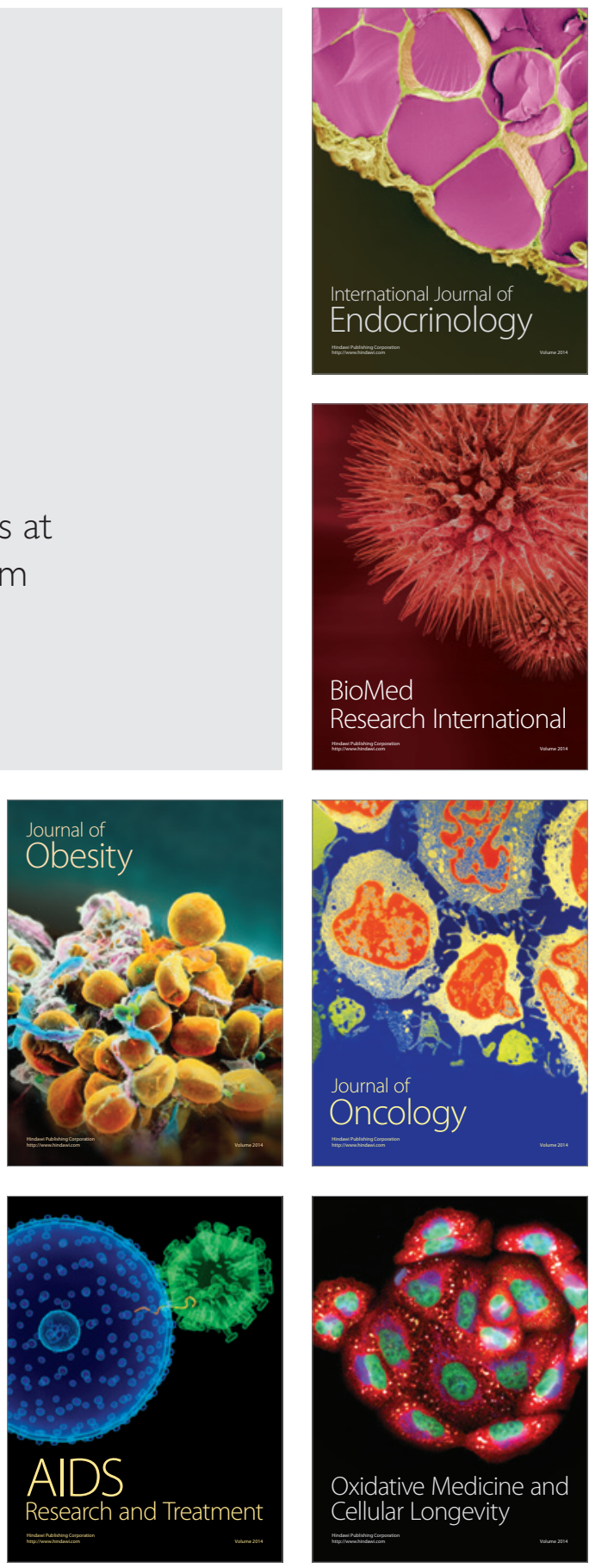